\title{
EL TRAUMA EN LA PIEL: UN ANÁLISIS PALEOPATOLÓGICO DE TATUAJES PARACAS-NECRÓPOLIS
}

\section{SOFT TISSUE TRAUMA: A PALEOPATHOLOGICAL ANALYSIS OF PARACAS-NECROPOLIS TATTOOS}

\author{
Patricia Karina Maita Agurto ${ }^{1}$ y Enma Minaya Cabello²
}

\begin{abstract}
RESUMEN
El tatuaje es un tipo de modificación cultural del cuerpo que consiste en insertar tinta dentro de las capas dérmicas a través de una aguja u otro material. La práctica del tatuaje causa un trauma en la piel con el objetivo de ejecutar un diseño conocido, cuyo resultado es una marca indeleble en el cuerpo. Este artículo analiza las consecuencias paleopatológicas del tatuaje en un conjunto de momias tatuadas del periodo Paracas Necrópolis procedentes del Cementerio de Warikayan, localizado en la costa sur del Perú. A partir de los resultados obtenidos de los análisis bioarqueológicos, complementados con los análisis de tatuajes mediante microscopia óptica, fluorescencia de rayos X y reflectografía infrarroja, se localizan los tatuajes y se inspeccionan en busca de lesiones derivadas de la práctica de modificación cultural. Los resultados indican que el $43 \%$ de los individuos Paracas analizados tiene tatuajes. Las localizaciones más frecuente para los tatuajes eran el dorso y la palma de la mano (21\%), los dedos de la mano (16\%) y el antebrazo (14\%), Se ha encontrado una prevalencia de tatuajes considerablemente alta en mujeres. El pigmento utilizado es el carbón y debido a la similitud de los diseños tatuados con aquellos registrados en mantos textiles y vasijas cerámicas de la cultura Paracas, es posible pensar que los tatuajes están relacionados con el estatus social.
\end{abstract}

Palabras clave: Tatuajes, Paracas, Necrópolis, paleopatología, tejido blando

\section{ABSTRACT}

Tattoos are intentional body modifications that describes the implantation of pigment into the dermis by a needle or other material. Tattooing cause trauma to the skin in order to execute a specific design. The result is an indelible mark in the skin. This article analyzes the paleopathological implications of tattooing and presents the results of the optical microscopy analisys, X-ray fluorescence and infrared Reflectography performed on a set of tattooed mummies from the Paracas Cemetery of Warikayan, located on the southern coast of Peru. All individuals analyzed are from the Paracas Necropolis period. The results indicate that $43 \%$ of the Paracas population had tattoos. The most common locations for tattoos were the hand (21\%), the fingers $(16 \%)$ and forearm (14\%). There was a significantly high prevalence of tattoos on women. The pigment used is coal. The similarity of the designs tattooed with those recorded in textiles and ceramic Paracas suggest that tattoos were associated with social status before they used as medical therapy

Keywords: Tatooing, Paracas, Necrópolis, paleopathology, soft tissue

Tipología: Artículo de Investigación Científica y Tecnológica

Fecha de recepción: 04/02/2014

Fecha de aceptación: 02/07/2014

Como citar este artículo: Maita, P. K. \& Minaya, E. E. (2014). El trauma en la piel: El registro de Tatuajes Paracas Necrópolis. Jangwa Pana, 13, 14 - 33

1. Museo Nacional de Arqueología, Antropología e Historia del Perú, Perú. Correo: pat_maita@hotmail.com

2. Museo Nacional de Arqueología, Antropología e Historia del Perú, Perú. Correo: enmamin@hotmail.com 


\section{INTRODUCCIÓN}

L os diversos estudios paleopatológicos de restos humanos momificados (Assis et al., 2013; Lombardi, 1994; Allison et al., 1981; Fornaciari et al., 1992; Hunt et al., 1996; Gerszten et al., 1991; Cockburn et al., 1998; Guerrero-Sala, 2002), demuestran que el campo de la paleopatología es amplio y es posible registrar enfermedades que comúnmente no dejan huellas sobre el hueso. En el análisis de momias, la presencia de piel puede brindar importante información sobre patologías y traumatismos del tegumento, algunos de ellos ocasionados por la modificación intencional del cuerpo, como el caso de los tatuajes, cuya ejecución ocasiona heridas que alteran la integridad del tejido blando.

El estudio de los tatuajes es inusual en paleopatología, a pesar que son reconocidos como traumas y mutilaciones tegumentarias (Aufderheide \& Rodriguez-Martin, 1998; Dembo \& Imbelloni, 1938). El tatuaje es la ejecución de diseños sobre el cuerpo humano mediante la inserción de pigmento insoluble bajo la epidermis. La práctica es realizada cuando el individuo está vivo y está relacionada a múltiples razones, entre las que cuentan la categoría social, la manifestación simbólica del rango, la estética y las exigencias mágico religiosas (Aufderheide \& Rodriguez-Martin, 1998; Dembo \& Imbelloni, 1938; Drewal \& Drewal, 1983; Faris, 1972; Field, 1958; Handy, 1922; Kapel et al., 1991; Searight, 1984; Swami $\&$ Harris, 2012). En restos humanos momificados en buen estado de conservación, los tatuajes son fácilmente reconocidos porque se observan diseños sobre la piel, cuyas tonalidades varían entre azuladas o negras que permanecen indelebles.

A partir del registro bioarqueológico de 47 individuos momificados procedentes del cementerio de Warikayan (500 a.C - 100 d.C), localizado en la costa sur del Perú, se ha logrado identificar el género y edades de los individuos que portan tatuajes. El análisis de microscopia óptica y fluorescencia de rayos $\mathrm{X}$ ha permitido caracterizar los pigmentos insertos dentro de la piel, mientras que con el uso de la reflectografía infrarroja se han localizado las lesiones tegumentarias específicamente ocasionadas por la modificación cultural del cuerpo, resultando especialmente útil en el caso Paracas Necrópolis, ya que la gran mayoría de los cuerpos se encuentran cubiertos por pintura funeraria corporal, ocultando en gran medida los tatuajes.

\section{El contexto cultural}

Warikayan es uno de los principales cementerios de la Cultura Paracas, el cual se localiza en el departamento de Ica, costa sur del Perú. El registro arqueológico indica que en esta área, a finales del periodo Horizonte temprano, se inició una práctica funeraria compleja, la cual consistía en envolver el cuerpo del difunto en múltiples capas de ropa y extensos mantos dotados de figuras simbólicas policromadas (Sawyer, 1960; Kaufmann, 1999; Vreeland, 1998). Dicho receptáculo funerario es conocido como fardo, cuya forma final era la de un bulto cónico de grandes dimensiones que podían alcanzar hasta el 1.60 metros de altura (Tello, 1956; Kaufmann, 1999)

El cementerio de Warikayan fue excavado entre 1927 y 1928 por Julio C. Tello junto a un equipo del Museo de Arqueología Peruana. En total se recuperaron 429 fardos funerarios, todos ellos correspondientes a la fase Paracas Necrópolis. Aproximadamente un centenar de ellos se ha abierto (Frame, 1991) y actualmente 47 cuerpos se encuentran disponibles para análisis en el Museo Nacional de Arqueología, Antropología e Historia del Perú.

La apertura de los fardos por Tello y su equipo evidenció que varios de los individuos presentaban buenas condiciones de preservación, conservando en gran parte tejido blando momificado (Tello y Mejía, 1979). Los fardos fueron abiertos hace 80 años, desde entonces han ocurrido diversos sucesos tales como descomposición de tejido blando, extracción de tejido momificado, 
autopsias, entre otras, que han determinado que actualmente las momias no se encuentren totalmente íntegras, por lo que muchas de ellas presentan hoy diversos grados de esqueletización.

Al observar los cuerpos Paracas es notorio que hubo una práctica muy intensa de modificar culturalmente la apariencia física del individuo, ya sea por medios temporales de ornamentación (pintura corporal, peinados, adornos) o permanentemente a través de la modificación intencional del cráneo y el tatuaje corporal. (Figura 1a. y b)
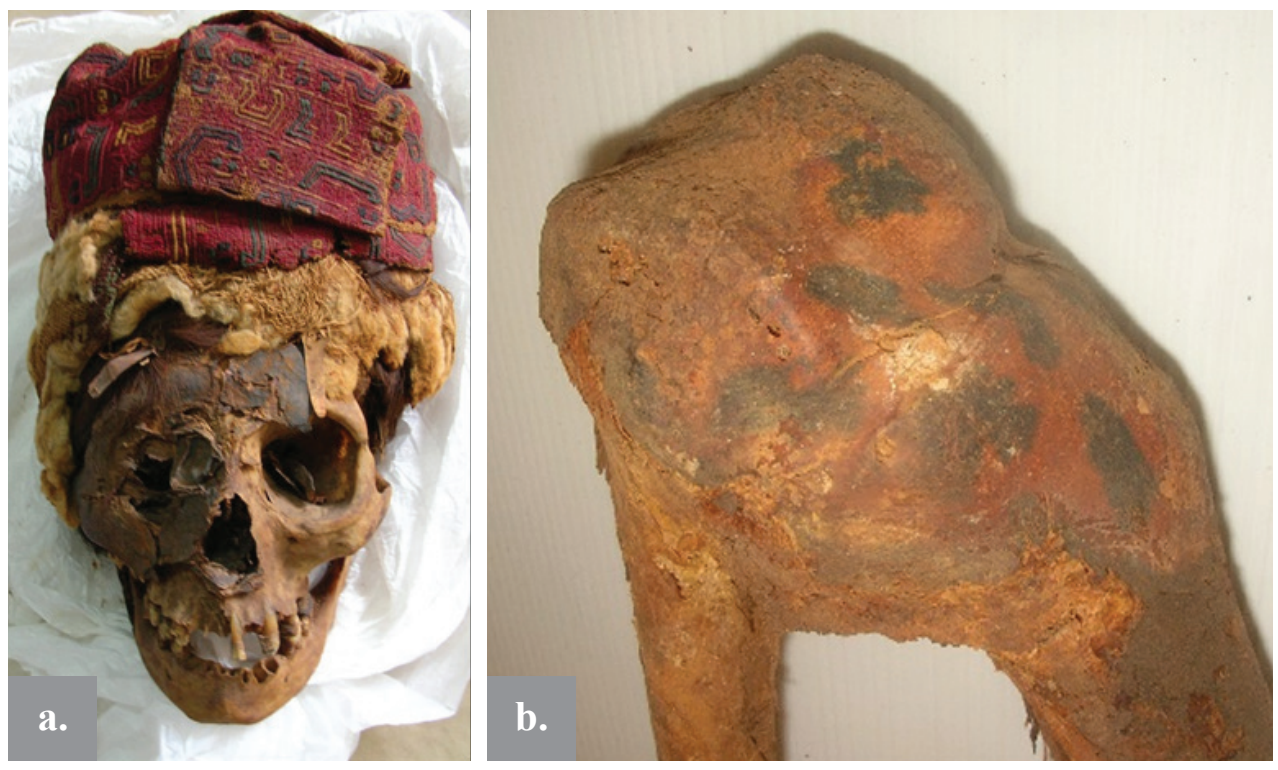

Figura 1. a. Tocado Paracas b. Tatuajes y pintura corporal sobre una rodilla momificada con tatuajes.

Como parte del ajuar funerario se ha hallado gran cantidad de marcadores de identidad y prestigio, los que han sido catalogados como símbolos de mandatarios (Yacovleff y Muelle, 1934; Paul, 1991; Sawyer, 1960; Kaufmann, 1999). Los restos humanos del Cementerio Warikayan, además de estar asociados a mantos textiles altamente ornamentados y cargados de una vasta iconografía, presentan una gran cantidad de adornos personales como diademas, narigueras, brazaletes, orejeras, collares de conchas marinas, penachos, pelucas, abanicos de plumas y varas de madera, lo que sugiere el uso de diversos elementos como marcadores personales y sociales.

\section{Implicaciones patológicas del tatuaje}

El hallazgo de cuerpos momificados a lo largo de los Andes ha permitido el registro de la práctica del tatuaje en diferentes sociedades prehispánicas (Stewart, 1943; Tello y Mejía, 1979; Allison et al. 1981; Ruiz, 1990; Ruiz, 1995; Allison, 1996; Vivar, 2008; Franco, 2008; Vásquez, 2013; Pabst et al., 2010). La práctica del tatuaje implica lesionar la piel para introducir pig- 
mentos, lo cual no está libre de posibles efectos adversos en el organismo.

Durante la elaboración del tatuaje, el pigmento es depositado a través de repetidas aplicaciones en la capa dérmica mediante inyección directa con aguja hasta formar un diseño reconocible. Las múltiples aplicaciones generan un traumatismo del tegumento cuya profundidad variará dependiendo de la compresión que el agente traumático produjo durante su penetración en la piel, mientras que la extensión de la herida dependerá del tamaño del diseño que se está tatuando.

Cuando se rompe la barrera epidérmica y el pigmento es insertado en la piel se desencadena una respuesta inflamatoria en la dermis y epidermis, iniciando con ello los procesos de fagocitosis y coagulación que detiene la pérdida de sangre (Crecelius, 2013, Fattahi 2011). Las partículas sólidas del pigmento son reconocidas por el organismo como un material extraño, por lo tanto son fagocitados. En este proceso se eliminan algunas de las partículas junto a tejido dañado, sin embargo debido a que el pigmento es insoluble este no puede ser destruido por las enzimas hidrolíticas de los lisosomas, ocasionando la muerte de los macrófagos dérmicos con el pigmento dentro de ellos (Aufderheide y Rodriguez-Martin, 1998).

Una vez finalizado el tatuaje, el aspecto será el de una herida expuesta, compuesta de múltiples traumatismos penetrantes que rompieron la piel. Junto a toda herida siempre habrá sensación de dolor ocasionado por la contusión de los tejidos producida por el traumatismo (Liebl et al. 2012). La intensidad del dolor dependerá de la extensión del tatuaje, de la ubicación anatómica de la lesión y del movimiento que realice el individuo. La aparición de edema y eritema localizados están asociados luego de un traumatismo cutáneo y pueden durar varios días dependiendo de la ubicación del tatuaje (Juhas et al. 2013).

La piel al ser un tejido esencialmente conectivo, se reparará de manera rápida de la lesión ocasionada por el tatuaje durante la fase proliferativa, mo- mento en que se produce un aumento de colágeno que da paso a la reepitelización y contracción de la herida (Arons et al., 1992). Finalmente, la herida desaparecerá alrededor de las dos semanas de haber finalizado el tatuaje, cuando la totalidad del colágeno se haya remodelado (Liebl et al., 2012; Hogsberg et al. 2012). A pesar de que el tatuaje pueda dañar un área extensa de tejido con miles de pequeñas heridas ocasionadas por la aguja que inyecta la tinta, la dermis tatuada se cura sin dejar cicatrices debido a que cada lesión provocada por la aguja es pequeña y la respuesta inflamatoria es mínima o está ausente (Stocum, 2012).

De acuerdo con la literatura médica, el tatuaje puede ocasionar muchas complicaciones y afectar a la piel mediante reacciones inflamatorias, infecciones bacterianas y virales, micosis, granulomas, alergias, tumores y enfermedades localizadas de la piel (Kazandjieva y Tsankov, 2007). Al romper la barrera cutánea, diversas infecciones localizadas pueden ser ocasionadas por bacterias estafilocócicas que habitan normalmente en la piel. Bacterias tuberculosas como Mycobacterium fortuitum, $M$ abscessus, $M$. haemophilum y $M$ chelonae pueden ocasionar prurito, pápulas y nódulos con úlceras expuestas debido al uso de agua no esterilizada para diluir los pigmentos del tatuaje (Drage et al. 2009; Juhas et al. 2013).

La práctica también puede convertirse en una fuente de transmisión de enfermedades infecciosas por vía hematógena, ya que agujas y pigmentos no esterilizados conteniendo bacterias patógenas y ambientales entran en contacto con capilares sanguíneos (Kazandjieva, y Tsankov 2007). Clínicamente se ha reportado el contagio de M. tuberculosis y M. leprae a través de tatuajes debido al uso de agujas no esterilizadas, agujas reutilizadas contaminadas con sangre o saliva del tatuador que usa para humedecer las agujas, el uso de pigmentos contaminados o la aplicación de tierra sobre los tatuajes recién hechos (Ghorpade, 2009; Brandsma et al., 2005; Juhas et al., 2013; Nishioka et al., 2001). 
Asimismo se conoce que después de ser inyectados, los pigmentos pueden expandirse ampliamente en el cuerpo, llegando a invadir mucosas adyacentes y ganglios linfáticos (Arons et al. 1992). Los pigmentos también pueden ser fotosensibles, especialmente aquellos obtenidos del carbón que ocasionan problemas transitorios en la piel hasta en un $9 \%$ de personas tatuadas, debido a la formación de oxígeno reactivo después de la exposición de los tatuajes a la luz solar (Lehner et al., 2011).

\section{MATERIALES Y MÉTODOS}

La colección de restos humanos Paracas procedentes del Cementerio de Warikayan consta de 47 individuos, custodiados actualmente por el Museo Nacional de Arqueología, Antropología e Historia del Perú (MNAAHP). El registro de tatuajes requiere necesariamente que los cuerpos conserven tejido blando momificado, en forma especial los tejidos que conciernen al tegumento, por lo que de acuerdo al objetivo del trabajo se excluyeron 27 individuos que presentaban esqueletización total y se seleccionaron 20 cuerpos con tejido blando en diferentes grados de preservación para ser incluidos en los análisis de reconocimiento de tatuajes. El grado de preservación de tejido blando de cada cuerpo fue calculado de acuerdo al sistema de puntuación STP (soft tissue preservation) desarrollado por Wittmers et al., (2011).

Todos los cuerpos presentan áreas cubiertas con tejido blando que coexisten con áreas esqueletizadas, siendo posible observar y registrar diversos huesos desarticulados que han perdido conexión anatómica del cuerpo momificado, por lo cual se decidió aplicar métodos osteológicos para la estimación de edad y sexo. En casos donde el cráneo y la pelvis se encontraron esqueletizados se optó por estimar la edad y el sexo utilizando los criterios estandarizados descritos por Buikstra y Ubelaker (1984). Las tablas de secuencia de de- sarrollo y erupción dental de Ubelaker (1999) fueron utilizadas cuando se logró observar directamente la mandíbula o el maxilar. Ante la presencia de huesos largos desarticulados se aplicaron los métodos de estimación de edad basado en la secuencia de fusión de epífisis (White y Folkens 2012).

La estimación de la edad está basada en criterios generales debido a que la conservación diferencial de tejido blando en los cuerpos no permite estimar edades específicas para cada individuo, ya que el área corporal cubierta con tejido momificado es variable. Se utilizaron las siguientes categorías de edad: adolescente (15-19 años), adulto joven (20-34 años), adulto medio (35-49 años) y adulto mayor (más de 50 años).

Los tatuajes fueron examinados visualmente. La superficie de la piel fue revisada usando una lupa de 10x de aumento, se registró y tomaron fotografías. A la luz natural sólo algunos tatuajes son visibles, los cuales aparecen oscuros y sin forma definida. La piel de las momias también es oscura, debido a que muchas de ellas presentan pintura negra o han sido expuestas al fuego como parte del tratamiento funerario (Tello, 1929), lo que obstaculiza en gran medida el registro de los tatuajes. En conclusión, el bajo contraste entre el tatuaje y la piel no permite registrar mayores detalles a simple vista.

Ante dicha problemática se utilizó un equipo de reflectografía infrarroja con el objetivo de mejorar la visibilidad de los tatuajes y registrar aquellos que se encuentran ocultos debido a la coloración oscura de las momias. Algunos tatuajes que son observables con luz natural también fueron examinados para registrar mayores detalles. La tecnología infrarroja es una técnica no invasiva que ha sido utilizada anteriormente en el estudio de tatuajes en momias del Ártico (Smith \& Zimmerman, 1975), Nubia (Armelagos 1969, Alvrus et. Al 2001) y Perú (Maita \& Minaya, 2013). La técnica también es usada en la investigación forense 
para mejorar la visibilidad de tatuajes que han sido removidos por láser o descubrir tatuajes que han sido cubiertos por otros dibujos (Clarkson \& Birch 2013, Bryson et al., 2013).

El equipo de reflectografía infrarroja utilizado en el registro de los tatuajes consta de una cámara de vídeo con filtro infrarrojo, una lámpara de radiación infrarroja y un monitor. Durante el proceso, cada espécimen momificado es iluminado con la lámpara de radiación infrarroja. La radiación emitida por la lámpara bloquea el espectro visible, por lo que la cámara de vídeo capta sólo la luz infrarroja y registra la capa subyacente que es oculta al ojo humano. La imagen es emitida en blanco y negro por el monitor y desde la pantalla se capta la imagen mediante fotografía digital.

Durante el registro de los tatuajes se tomaron en cuenta la descripción de los diseños, cantidad y ubicación por zona corporal. Las zonas corporales registradas corresponden a cara, orejas, hombros, brazo, antebrazo, muñeca, mano (palma y/o dorso), dedos de la mano, muslo, rodilla, pierna, tobillo y pie. Espalda y abdomen no fueron tomadas en cuenta debido a que no se ha preservado tejido momificado de estas zonas en la muestra analizada. El registro de la cantidad de tatuajes se realizó para cada región corporal utilizando las siguientes categorías: U: Único (1 tatuaje), P: Pocos (de 2 a 5 tatuajes), V: Varios (de 6 a 10 tatuajes) y C: Concentrados (de 10 a más). El cálculo del área corporal tatuada se realizó utilizando los criterios de Chi-Yuang, et al. (2010).

Adicionalmente los análisis se complementaron con microscopia óptica. Cinco micromuestras de tejido blando con tatuaje fueron cuidadosamente retiradas de áreas donde no se notara una pequeña pérdida de tejido. Las observaciones realizadas en microscopio óptico se realizaron para identificar los pigmentos que fueron insertados dentro de la piel, asimismo se buscaba verificar la ubicación de los pigmentos dentro del tejido blando momificado. Todas las muestras fueron documentadas y fotografiadas. Las muestras analizadas se presentan en la Tabla 2.

Las muestras fueron observadas previamente en el estereoscopio y se verificó que la superficie de las mismas no contuviera partículas contaminantes. Mediante corte transversal se examinó el tejido momificado, a fin de verificar que los depósitos de pigmento se encontraran insertos en la piel. Todas las muestras fueron disgregadas con glicerina y frotadas con una aguja enmangada sobre un portaobjeto para lograr la dispersión de las partículas del pigmento.

Los resultados de las muestras observadas al microscopio óptico se compararon con patrones de pigmentos orgánicos e inorgánicos disponibles en el Laboratorio Químico del MNAAHP. Adicionalmente se realizó un análisis elemental de compuestos inorgánicos con el fin de identificar constituyentes de los pigmentos, para lo cual se utilizó un equipo portátil de fluorescencia de rayos $\mathrm{X}$

Todos los datos fueron procesados con SPSS versión 14.0. Se utilizó estadística descriptiva para calcular el promedio y la desviación estándar. La información se presenta de acuerdo a los criterios utilizados en paleoepidemiologia, por lo cual el término prevalencia es usado aquí como el cálculo de la proporción de individuos con una determinada patología dentro de una población específica (Cockburn, et al, 1998; Ortner, 2011; Smith, 2013)

\section{RESULTADOS}

\section{Estado de momificación}

El promedio de la puntuación para el grupo de cuerpos con tejido momificado es de 0.42 (S.D = $0.18)$. La puntuación de cada cuerpo se presenta en porcentaje (puntuación STP x 100\%) en la 
tabla 1. Los cuerpos preservan entre $10 \%$ y $72 \%$ de tejido blando momificado, principalmente en la cabeza, extremidades inferiores y extremidades superiores.

Tabla 1. Numero de momia, sexo y edad de los individuos momificados analizados, indicando el porcentaje de preservación de tejido blando (STP), numero de regiones corporales con tatuaje y superficie corporal tatuada.

\begin{tabular}{|c|c|c|c|c|c|}
\hline $\begin{array}{c}\text { Numero } \\
\text { de momia } \\
(n=20)\end{array}$ & Sexo & $\begin{array}{c}\text { Categoría de } \\
\text { edad }\end{array}$ & $\begin{array}{c}\text { Puntaje } \\
\text { STP } \\
\text { Porcentaje } \\
(\%)\end{array}$ & $\begin{array}{l}\text { Numero de } \\
\text { regiones } \\
\text { corporales } \\
\text { con tatuaje }\end{array}$ & $\begin{array}{c}\text { Superficie } \\
\text { corporal } \\
\text { tatuada } \\
(\%)\end{array}$ \\
\hline 12 & Femenino & adulto medio & 58 & 2 & 4.6 \\
\hline 28 & Femenino & adulto mayor & 44 & 3 & 8.1 \\
\hline 29 & Femenino & adulto medio & 18 & 1 & 2.3 \\
\hline 30 & Femenino & adulto medio & 48 & 1 & 2.3 \\
\hline 32 & Femenino & adulto mayor & 16 & 1 & 1 \\
\hline 66 & Femenino & adolescente & 48 & 1 & 2.3 \\
\hline 70 & Femenino & adulto medio & 54 & 10 & 49.5 \\
\hline 73 & Femenino & adulto medio & 46 & 5 & 11.4 \\
\hline 81 & Femenino & adulto medio & 34 & 7 & 35.5 \\
\hline 85 & Masculino & adulto medio & 10 & 1 & 1.0 \\
\hline 86 & Femenino & adulto medio & 58 & 5 & 21.4 \\
\hline 87 & Femenino & adulto medio & 72 & 7 & 44.9 \\
\hline 110 & Masculino & adulto medio & 24 & 4 & 8.9 \\
\hline 199 & Masculino & adulto medio & 56 & 1 & 2.4 \\
\hline 234 & femenino & adulto medio & 40 & 6 & 16.2 \\
\hline 319 & masculino & adulto medio & 72 & 3 & 7.9 \\
\hline 355 & masculino & adulto medio & 24 & 1 & 3.4 \\
\hline 420 & masculino & adulto medio & 28 & 1 & 2.4 \\
\hline 437 & femenino & adulto medio & 36 & 9 & 32.1 \\
\hline 451 & masculino & adulto medio & 52 & 1 & 1.2 \\
\hline \multicolumn{3}{|c|}{ Promedio } & 0.42 & 3.5 & 0.13 \\
\hline \multicolumn{3}{|c|}{ S.D. } & 0.18 & 2.9 & 0.16 \\
\hline
\end{tabular}

\section{Prevalencia de tatuajes en la población Paracas}

El 100\% (20/20) de los individuos que conservan tejido momificado presentan tatuajes. Si consideramos la muestra total de 47 individuos que corresponden al número total de individuos que se dispone en los depósitos del MNAAHP, tendríamos que la prevalencia de tatuajes en la población Paracas es de $43 \%(20 / 47)$. 
El mayor número de cuerpos con tatuaje corresponden a mujeres $(13 / 20=$ $65 \%$ ), mientras que el 35\% (7/20) son hombres (Figura 2).

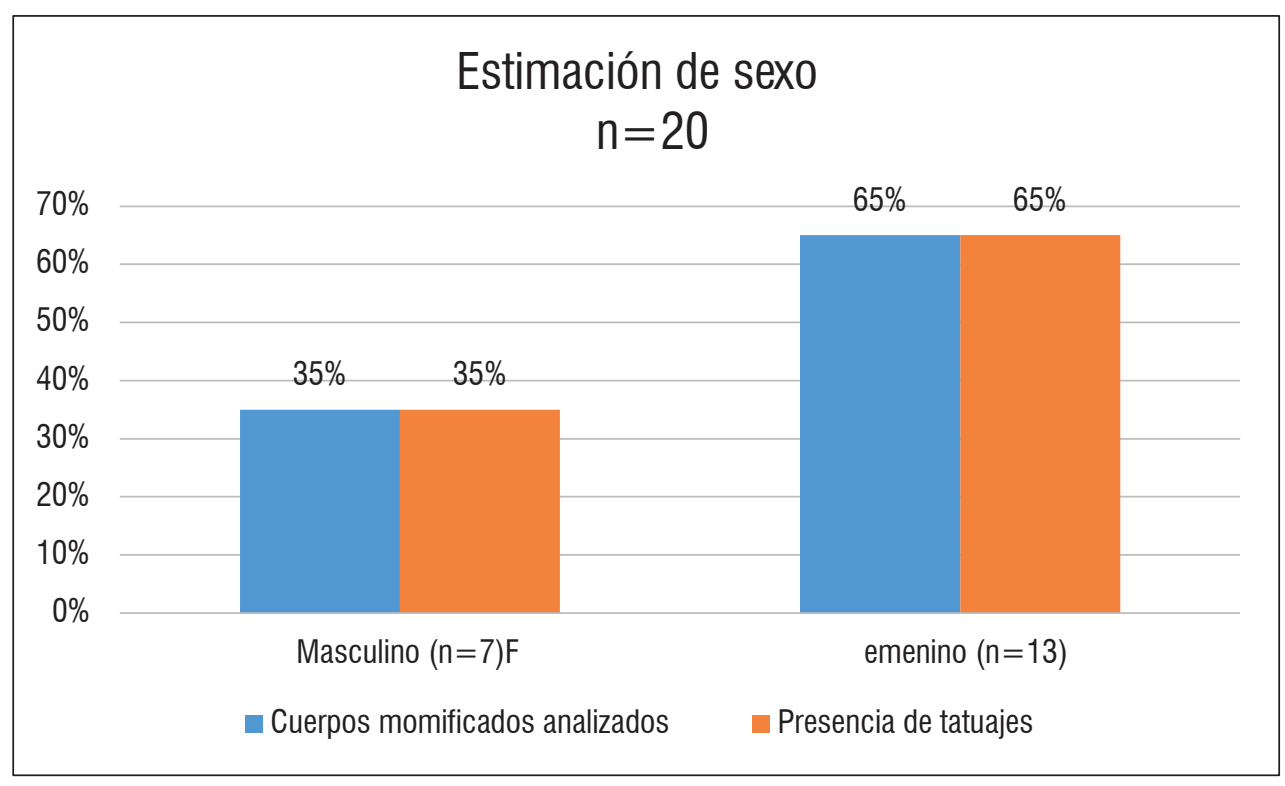

Figura 2. Distribución de la muestra. Individuos momificados por sexo y presencia de tatuajes.

Existen diferencias significativas entre las categorías de edad (figura 3), el $85 \%(17 / 20)$ de los individuos con tatuaje corresponden a la categoría adulto medio (35-49 años de edad). El individuo más joven de la muestra corresponde a un adolescente del sexo femenino. Los adultos mayores representan al $10 \%(2 / 20)$ de la muestra total y corresponden a individuos femeninos. La edad del $100 \%$ de individuos masculinos se encuentra en la categoría adulto medio.

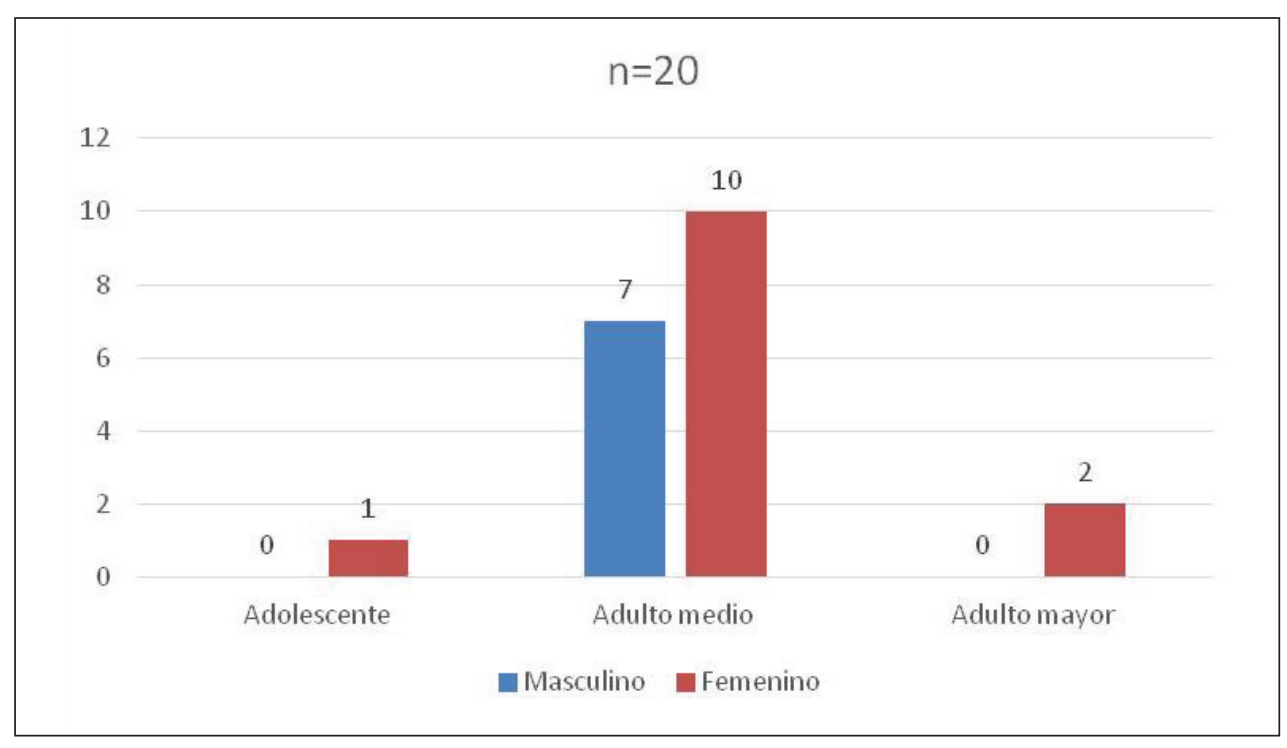

Figura 3. Categoría de edad y sexo de individuos momificados con tatuajes. 
En promedio, los individuos tienen 3.5 regiones corporales con tatuajes (S.D $=2.9$ ). El número de regiones corporales tatuadas en mujeres cubre un rango de 1 a 10, mientras que en hombres el rango es de 1 a 4 , habiéndose registrado 10 regiones corporales tatuadas en la momia 70 como el caso de mayor cantidad, mientras que una (01) región corporal sería el mínimo, como los casos de las momias 85, 199, 355, etc. (Tabla 1).

Los cuerpos tienen en promedio el $13 \%$ de su superficie corporal tatuada $(\mathrm{S} . \mathrm{D}=0.16)$. La modificación corporal es más intensa en el caso de mujeres que en hombres, observándose que el número promedio de regiones corporales tatuadas por individuo femenino es 4.5 (S.D.=3.4), mientras que por individuo masculino es 0.9 (S.D. $=1.3$ ). Al examinar la superficie corporal tatuada se observa que los tatuajes cubren áreas más extensas en los cuerpos femeninos que en los masculinos, como ejemplo se puede citar los casos de las momias 87 y 70 , ambas femeninas, las cuales presentan $44.9 \%$ y $49.5 \%$ respectivamente de superficie corporal tatuada (figura 4).

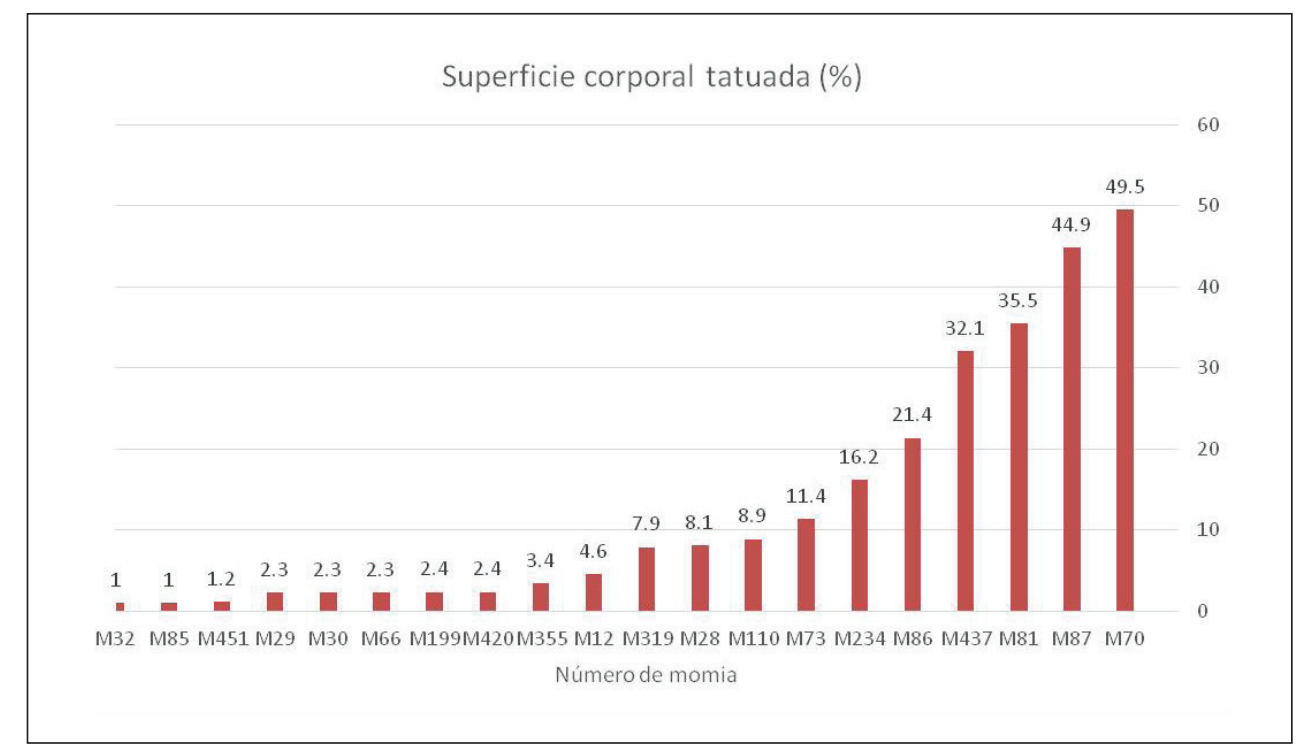

Figura 4. Porcentaje de superficie corporal tatuada.

\section{Pigmentos utilizados en el tatuaje}

Una observación de la superficie de la piel con lupa de 10x no reveló daño tegumentario. Asimismo la revisión bajo el estereoscopio y microscopio óptico no reveló cicatrices evidentes sobre la piel.

Las observaciones al microscopio de las cinco muestras de piel tatuada revelaron que los depósitos de pigmento se hallan insertos en el tejido blandoº

3. Se ha optado por usar el término tejido blando para hacer referencia a alguna de las capas dérmicas dónde se encuentran los depósitos de pigmento, las cuales no pueden diferenciarse ante la falta de análisis histológicos. Al observar que los depósitos se encuentran dentro de tejido blando, confirmamos que verdaderamente se tratan de tatuajes, ya que los pigmentos están insertos en la piel y no se ubican en la superficie de la piel, lo cual sería compatible con pintura corporal. 
dentro de la piel, mientras que el espesor de los tatuajes fluctúa entre 50 a $100 \mu \mathrm{m}$. Al examinar los pigmentos al microscopio se observaron partículas suspendidas muy finas en estado amorfo, de 1 a $2 \mu \mathrm{m}$ de diámetro, siendo identificadas por comparación con patrones como negro de carbón (C) en la forma de negro de humo, también conocido como hollín (tabla 2). La mayor parte del pigmento se ha encontrado como conglomerado.

Tabla 2. Muestras de piel tatuada observadas al microscopio óptico.

\begin{tabular}{|c|c|c|c|}
\hline Momia & Ubicación del tatuaje & Diseño del tatuaje & Pigmento identificado \\
\hline 73 & Antebrazo izquierdo & Ictiomorfo & Negro de humo (hollín) \\
\hline 70 & Muslo derecho & Ictiomorfo & Negro de humo (hollín) \\
\hline 81 & Pierna izquierda & ornitormorfo & Negro de humo (hollín) \\
\hline 86 & Antebrazo derecho & Bandas geométricas & Negro de humo (hollín) \\
\hline 110 & Mano derecha & Puntos & Negro de humo (hollín) \\
\hline
\end{tabular}

\section{Los diseños}

La reflectografía infrarroja ha permitido registrar nueve diseños (ver tabla 3), muchos de los cuales son visualmente idénticos a la iconografía registrada en cerámica y textiles del estilo Paracas Necrópolis (ver figuras 5 y 6).

Tabla 3. Diseños tatuados identificados en las Momias Paracas Necrópolis.

\begin{tabular}{|c|c|c|c|}
\hline Categoría & Diseño & Presentación & Localización anatómica \\
\hline \multirow{3}{*}{ Zoomorfos } & Ictiomorfos & Agrupados & $\begin{array}{c}\text { Brazos, antebrazos, manos, } \\
\text { muslos, piernas }\end{array}$ \\
\hline & Aves & Agrupados & $\begin{array}{l}\text { Brazos, antebrazos, manos, } \\
\text { muslos, piernas, tobillos, pie }\end{array}$ \\
\hline & Felinos & Agrupados & manos \\
\hline \multirow{3}{*}{ Geométricos } & Puntos & $\begin{array}{c}\text { Solos } 0 \\
\text { agrupados }\end{array}$ & Dedos de las manos \\
\hline & Líneas & $\begin{array}{c}\text { Solos } 0 \\
\text { agrupados }\end{array}$ & $\begin{array}{l}\text { Antebrazos y manos (palma y } \\
\text { dorso) }\end{array}$ \\
\hline & Círculos & $\begin{array}{l}\text { Solos } 0 \\
\text { agrupados }\end{array}$ & $\begin{array}{l}\text { Oreja, hombros, muslos, } \\
\text { piernas }\end{array}$ \\
\hline \multirow{2}{*}{$\begin{array}{c}\text { Figuras } \\
\text { míticas y } \\
\text { sobrenaturales }\end{array}$} & Ser oculado & Solo & Palma de la mano \\
\hline & Orca asesina & Agrupados & Dorso de la mano, rodilla \\
\hline
\end{tabular}




\begin{tabular}{|c|c|c|c|}
\hline Categoría & Diseño & Presentación & Localización anatómica \\
\hline $\begin{array}{c}\text { Símbolos } \\
\text { sociales }\end{array}$ & $\begin{array}{c}\text { Greca } \\
\text { escalonada }\end{array}$ & Agrupados & Dorso de la mano \\
\hline Abstractos & Indeterminado & Agrupados & Antebrazos, rodillas, piernas \\
\hline
\end{tabular}
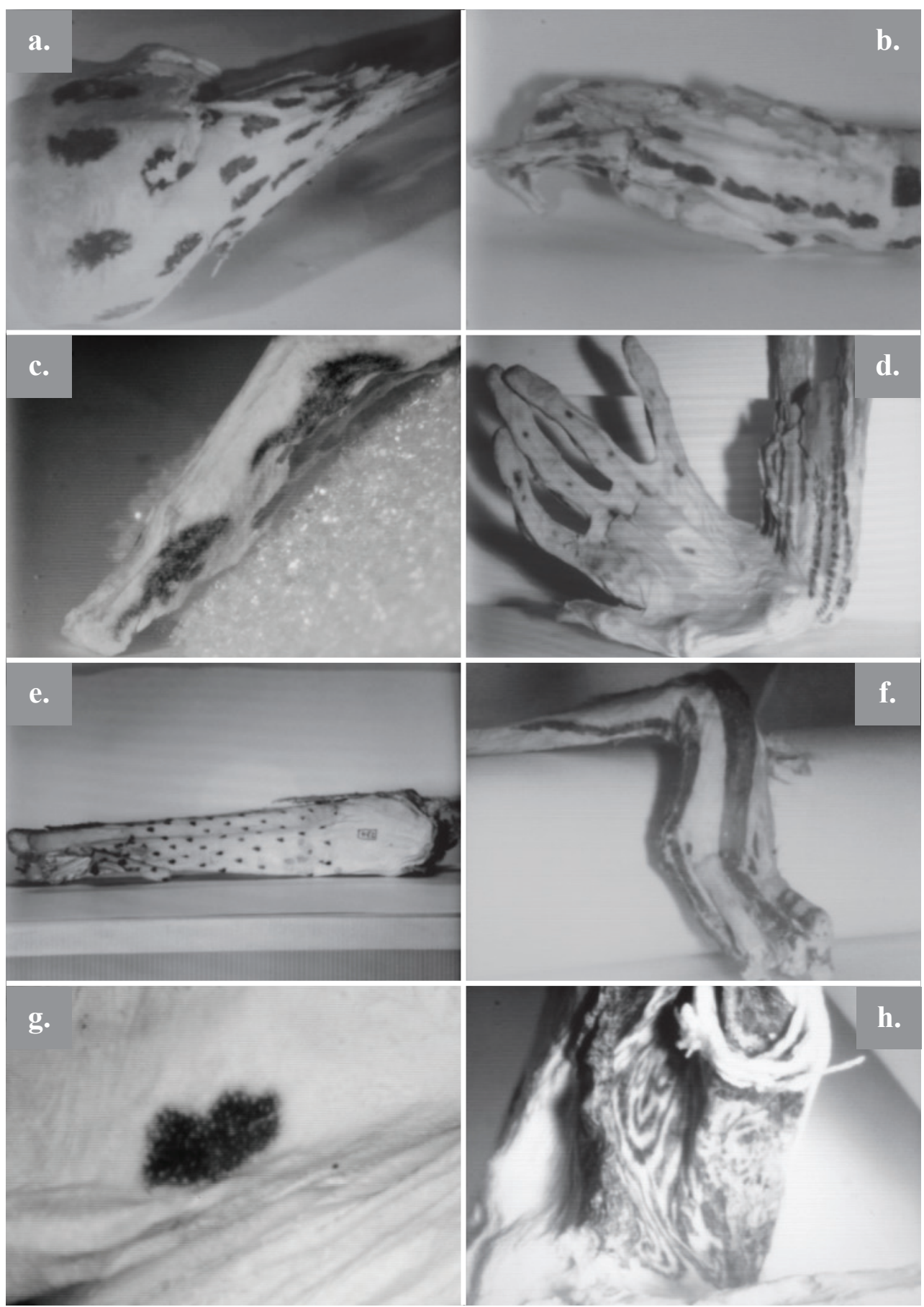

Figura 5. A. Miembro inferior izquierdo con diseños ictiomorfos tatuados. Fotografía obtenida con reflectografía infrarroja. B. Mano derecha con tatuajes de diseños ornitomorfos y geométricos. Fotografía obtenida con reflectografía infrarroja. C. Felinos tatuados 
en el dorso de la mano. Fotografía obtenida con reflectografía infrarroja. D. Miembro superior izquierdo con tatuajes de puntos sobre la palma de la mano y antebrazo. Fotografía obtenida con reflectografía infrarroja. E. Pierna derecha con tatuajes de puntos agrupados. Fotografía obtenida con reflectografía infrarroja. F. Miembro superior derecho con tatuajes de líneas gruesas sobre el antebrazo y dorso de la mano. Fotografía obtenida con reflectografía infrarroja G. Figura abstracta tatuada sobre el rostro. Fotografía obtenida con reflectografía infrarroja. H. Tatuaje del "ser oculado" sobre la palma de la mano. Fotografía obtenida con reflectografía infrarroja
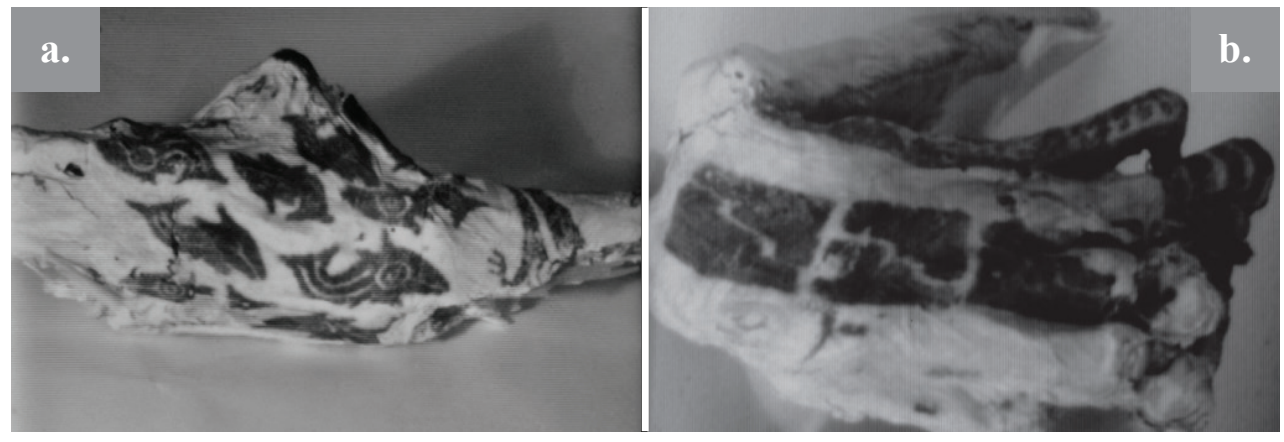

Figura 6. A. "Orcas asesinas "tatuadas sobre la mano izquierda. Fotografía obtenida con reflectografía infrarroja B. Diseño de greca escalonada tatuada sobre el dorso de la mano, adicionalmente se observa puntos y líneas sobre los dedos. Fotografía obtenida con reflectografía infrarroja

Los diseños zoomorfos constan principalmente de peces y aves. Los tatuajes de peces se representan en conjuntos de 10 a más, principalmente sobre los miembros superiores e inferiores (figura 5a), mientras que los diseños de aves se presentan en grupos de 5 a 10 figuras dispuestas en forma lineal (figura 5b). Los felinos han sido hallados sólo en un caso, presentándose en grupo de dos dispuestos en forma lineal sobre el dorso de la mano (figura 5c).

Otros diseños corresponden a símbolos geométricos como puntos, líneas y círculos, los que pueden estar solos o agrupados. Los puntos solos se encuentran especialmente sobre los dedos de la manos (figura 2d), mientras que al estar agrupados se observan sobre los miembros inferiores (figura 5e). Otros diseños geométricos como líneas se registran generalmente en el dorso y palma de las manos (figura 5f). Figuras abstractas o generalizadas se han observado sobre el rostro (figura $5 \mathrm{~g}$ )

Existen figuras míticas y sobrenaturales, tales como el ser oculado (figura $5 \mathrm{~h}$ ) y la orca asesina (figura $6^{\mathrm{a}}$ ). La greca escalonada, un símbolo que denota poder social, ha sido hallado cubriendo casi toda la mano de la momia 86, la cual a simple vista parece ser una mancha rectangular, pero observado con reflectografía infrarroja se observa claramente el diseño (figura 6b) 


\section{Ubicación de los tatuajes}

Se identificaron 13 zonas corporales que presentan tatuajes (figura 7). Las localizaciones más frecuente para los tatuajes son la mano (21\% en total). E1 33\% de las mujeres y $19 \%$ de los hombres tenían tatuajes en las manos. Tatuajes en los dedos de la mano se observó en el 16\% de las mujeres y $17 \%$ de los hombres, mientras que $14 \%$ del total tenía tatuajes en el antebrazo. Sin embargo se observa que los miembros inferiores son las regiones que están cubiertas con mayor número de tatuajes, las cuales suelen contener de 10 a más diseños, que específicamente corresponden a diseños zoomorfos que cubren las regiones anterior y posterior de muslos y piernas. La región menos tatuada es la cara, habiéndose registrado sólo 2 casos que corresponden a individuos femeninos.

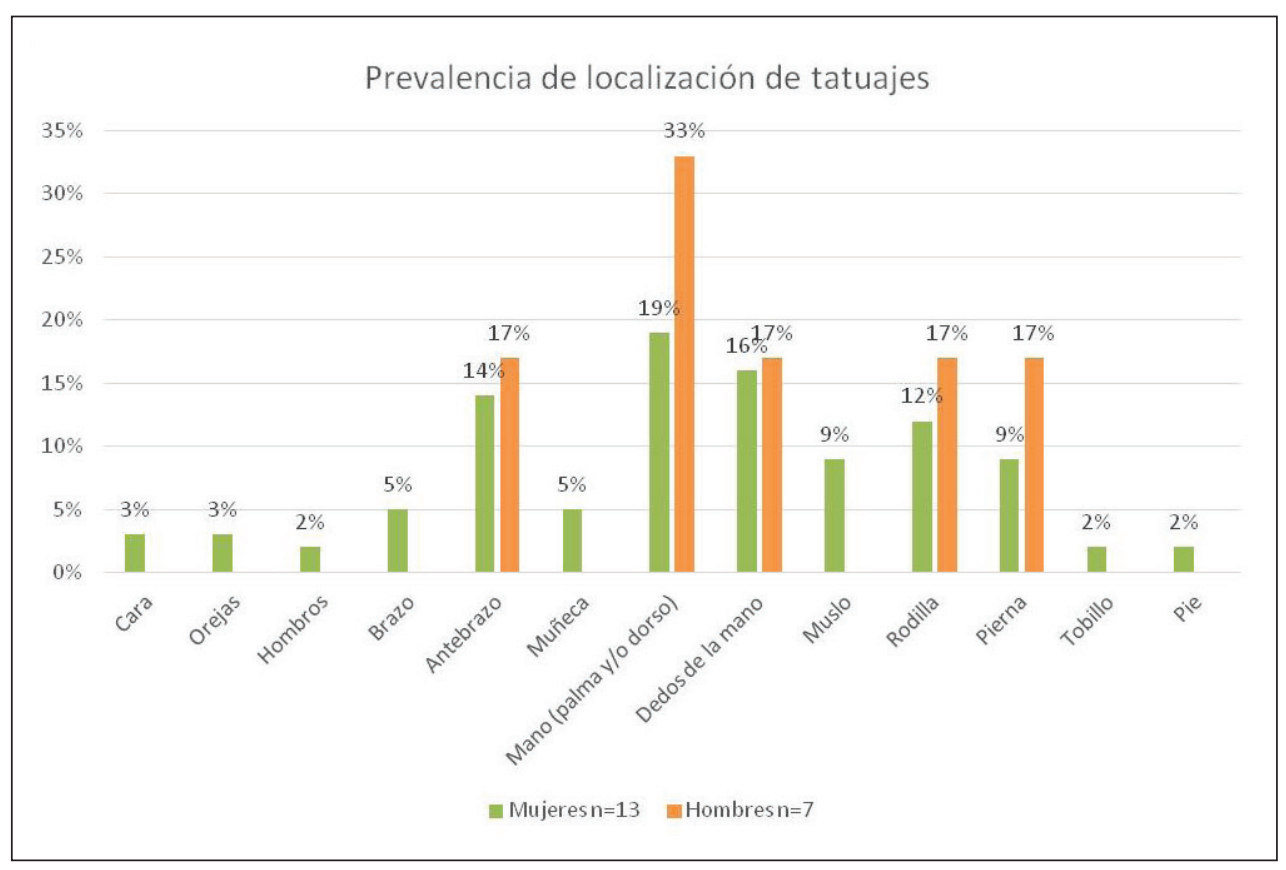

Figura 7. Prevalencia de localización de tatuajes

\section{DISCUSIÓN}

Tatuajes y otras formas de modificación corporal son prácticas que se han registrado en diferentes sociedades prehispánicas andinas en diversos periodos de tiempo. El tatuaje más antiguo en Sudamérica ha sido reportado en momias Chinchorro de 6,000 años de antigüedad (Allison 1996). En los Andes peruanos, se cuentan con algunos registros en culturas posteriores como Chimú, Chancay y Chincha quienes practicaron el tatuaje entre los 800 a 1400 d.C (Allison et al. 1981). Ruiz $(1990,1995)$ ha reportado el hallazgo de varias momias tatuadas del periodo Intermedio Tardío (1000-1200 d.C) halladas en 
Huacho, al norte de Lima. De la misma época corresponde una momia tatuada hallada en Huaura (Vivar 2008). Últimamente se ha reportado el hallazgo de una mujer con tatuajes conocida como "la Señora de Cao" del periodo Moche temprano (200-800 d.C) hallada en la costa norte del Perú (Vásquez 2013; Franco 2008). Del extremo sur peruano se conoce el hallazgo de una momia tatuada de la Cultura Chiribaya Alta (Pabst et al. 2010). Los tatuajes Paracas han sido reportado previamente por Stewart (1943) y Tello \& Mejía (1979), quienes describen el hallazgo de varios tatuajes de color azul y negro, siendo los diseños más frecuentes aquellos que corresponden a aves, estrellas y peces, encontrándose generalmente estos en el antebrazo, piernas y tórax.

\section{Prevalencia}

La prevalencia de tatuajes en la población Paracas Necrópolis es de 43\% (20/47). Aunque esta muestra podría no ser representativa de la población Paracas en términos que el estado de esqueletización del 57\% (27/47) de los cuerpos podría estar condicionado la ausencia del registro de tatuajes en varios de ellos, los resultados sin embargo se encuentran en concordancia con reportes anteriores de tatuajes en poblaciones arqueológicas andinas que señalan una prevalencia entre 30\% y 43\% para población adulta (Allison et al, 1981; Allison, 1996)

La presencia del tatuaje es particularmente pronunciada en individuos del sexo femenino, lo cual corresponde al $65 \%$ del total analizado (ver figura 1), presentando en promedio 4.5 (S.D. = 3.4) regiones corporales tatuadas, mientras que el grupo masculino solo reporta $0.9($ S.D.= 1.3) regiones corporales tatuadas (ver tabla 1 ), lo que indica que la muestra no pueden considerarse como un grupo homogéneo. La muestra ofrece la oportunidad de investigar a grupos separados por sexo. Asimismo es importante anotar que los porcentajes de superficie corporal tatuada es mayor en individuos femeninos que en los masculinos (figura 4).
Los resultados indican que las manos son las localizaciones más frecuentes para ubicar los tatuajes $(21 \%)$, sin embargo, es necesario señalar que la mayor representatividad de unas partes corporales sobre otras podría estar alterada por la falta de integridad de las momias, considerando que no todo el cuerpo se ha momificado ni todos los cuerpos están completos.

\section{Implicaciones paleopatológicas del tatuaje}

Aunque en raras ocasiones las lesiones en la piel dejarán una marca visible que sea similar al ca1 o óseo en el hueso, en tejido momificado será posible inferir las lesiones ocasionadas por la práctica del tatuaje a partir de los depósitos de pigmentos que quedaron insertos en forma permanente dentro de la piel, los cuales constituyen una evidencia directa de la práctica.

Una revisión con la lupa de aumento evidencia que en todos los casos, independientemente de la edad del individuo, hubo remodelación tegumentaria total. Los tatuajes no dejan cicatrices (Stocum, 2012) por lo que no será posible encontrar lesiones de la aguja en la piel, al menos que el tatuaje haya sido realizado en un momento muy cercano a la muerte, con lo cual se habría detenido la reepitelizacion y contracción de la piel en caso de una herida reciente. De acuerdo con nuestras observaciones, la muestra analizada indica que los tatuajes fueron realizados con mucha antelación antes que el individuo muriera, por lo que la regeneración celular dérmica ha logrado borrar toda evidencia de heridas en la piel.

Al no haber hallado cicatrices evidentes en la superficie de la piel, no ha sido posible determinar la técnica de tatuado. Allison et al. (1981) describe dos técnicas para introducir los pigmentos bajo la piel, mediante hincada directa con un objeto punzante y la del "cosido", esta última observada en una sección histológica de piel tatuada correspondiente a un individuo y que trataría de un hilo revestido de pigmento que se pasaba bajo 
la piel, dejando con ello una línea de pigmento en el tegumento. En las observaciones al microscopio del tejido blando extraído de las momias Paracas hemos observado pequeños depósitos de pigmento cuyo grosor varía entre 50 a 100 $\mu \mathrm{m}$, es decir que el pigmento bajo la piel no se observa como una línea homogénea, sino como una concentración de pigmento cuyo grosor varía, estando algunas partículas sobre o debajo de dicha concentración, por lo que suponemos que los tatuajes han sido realizados mediante el uso de agujas delgadas que dejaron partículas de pigmento a diferentes profundidades. Diversos medios como huesos, espinas o agujas impregnadas de pigmento pudieron ser utilizados. Debido a la técnica, los tatuajes dejarían lesiones muy finas de forma circular, dispuestas de forma agrupada sobre la piel.

Numerosas complicaciones que van desde dolor e inflamación de la piel hasta infecciones sistémicas graves por microorganismos bacterianos y virales han sido asociados a los tatuajes (Arons et al. 1992; Ghorpade 2009; Brandsma et al. 2005, Drage et al. 2009; Juhas et al. 2013, Nishioka et al. 2001; Kazandjieva et al., 2007; Lehner et al., 2011), debido a una insuficiente higiene personal, por la falta de desinfección en los establecimientos que realizan tatuajes (Kazandjieva et al., 2007) o alergias asociadas al pigmento de carbón (Lehner et al., 2011). Es posible pensar que la práctica antigua del tatuaje, posiblemente al carecer de los protocolos de esterilidad e higiene que se manejan hoy en día, pudo haber sido realizado con agujas y pigmentos contaminados, lo que pudo haber ocasionado diversas infecciones en el organismo, sin embargo en las momias Paracas es notorio que sobre la piel momificada no se hayan encontrado alteraciones dérmicas asociadas a los tatuajes que sugieran algún tipo de reacción o enfermedad. Es posible que de haberse presentado alguna complicación local de la piel, tales como reacciones alérgicas, pruritos o pápulas, estás hayan sido transitorias y superadas por el organismo dentro de las dos semanas de haber sido finalizado el tatuaje, tiempo que según la literatura clínica tarda la piel en regenerarse completamente (Hogsberg et al. 2012).

\section{Pigmentos utilizados}

Nuestras observaciones bajo microscopio óptico indican que se utilizó carbón bajo la forma de hollín como pigmento para realizar los tatuajes. El análisis elemental con fluorescencia de rayos $\mathrm{X}$ permitió identificar impurezas de hierro (Fe), cobre $(\mathrm{Cu})$ y silicio $(\mathrm{Si})$ como partículas constituyentes de las sales del pigmento negro de humo. Estos resultados son similares a las impurezas halladas entre las partículas de hollín de los tatuajes del hombre de hielo, los que probablemente derivan de las piedras de la chimenea de donde se obtuvo el hollín para el tatuaje (Pabst, 2009).

El uso de carbón en tatuajes ha sido reportado en diversas culturas alrededor del mundo (Spindler 1994, Allison 1996, Zimmerman, 1980). Según Allison (1996), el hollín fue utilizado para obtener los tonos negros y azulados de los tatuajes. Aunque se desconoce la forma cómo el carbón era obtenido y procesado, se ha sugerido que pudo ser raspado de la superficie exterior de lámparas, ollas o chimeneas que estuvieron expuestas al fuego (Zimmerman, 1980; Pabst, 2010).

Aunque el pigmento obtenido del hollín es negro, en algunos casos los tatuajes se perciben como de tonos azules sobre las momias. Esta distorsión es explicada por el efecto Tyndall, una consecuencia óptica de la retrodispersión de la luz azul desde la dermis a la melanina dérmica. El carbón del pigmento al absorber luz en la dermis, causa una coloración azul de la piel porque tiende a perder la luz de longitud de onda larga roja (Wolff et al., 2009). La coloración final de los pigmentos del tatuaje variará dependiendo de la composición química del pigmento y su localización anatómica dentro de la piel, a la cual se suman los colores de los diferentes cromóforos que existen en la epidermis y dermis, incluyendo melanina, hemoglobina y colágeno. (Longo et al., 2013; Aufderheide y Rodriguez-Martin, 1998). 
Alternativamente al hollín, diversas culturas han usado agentes colorantes de tonos negros derivados de plantas y la pólvora (Searight 1984, Pabst et al. 2010). En el caso de la región andina, se ha identificado el uso de carbón, posiblemente hollín, en tatuajes decorativos de una momia Chiribaya Alta del sur peruano, aunque el mismo individuo presenta otros tatuajes geométricos realizados con tintes orgánicos, posiblemente material vegetal quemado (Pabst et al. 2010). Los análisis realizados a los tatuajes de la Dama de Cao señalan que se empleó óxido ferroso como tinte, posiblemente extraído de un fruto inmaduro de Genipa americana L. (Vásquez et al. 2013).

\section{Función de los tatuajes}

El uso de tatuajes como recursos médicos ha sido discutido por Spindler (1994) en el estudio de Ötzi, conocido como el hombre de hielo, el cual presenta varios tatuajes de líneas pequeñas sobre áreas que osteológicamente evidencian cambios degenerativos. La ubicación de ciertos tatuajes sobre lugares comúnmente usados en la acupuntura ha llevado a pensar que los tatuajes eran utilizados para propósitos terapéuticos (Dorfer et al., 1988, 1999; Moser et al., 1999; Pabst et al. 2010). Según Alvrus et al. (2001) algunos tatuajes pudieron ser usados para propósitos médicos, ya que de forma similar a las cauterizaciones podrían ayudar a aliviar el dolor y promover la curación en un área enferma al aumentar el flujo sanguíneo hacia dicha área del cuerpo.

Al parecer, la ubicación corporal de los tatuajes, los diseños plasmados y el tinte empleado podrían dar indicios sobre una función decorativa o terapéutica de los tatuajes. Pabs et al. (2010) registraron una momia de Chiribaya Alta del sur peruano cuyos tatuajes decorativos, principalmente diseños zoomorfos y símbolos habían sido realizados con carbón, posiblemente hollín. Sin embargo, los círculos tatuados en el cuello habían sido realizados con tintes orgánicos, quizás material vegetal quemado. Pabs et al (2010) presume que los tatuajes del cuello podrían ser terapéuticos o realizados con fines de protección, ya que su ubicación coincide con puntos de acupuntura que son estimulados para aliviar dolores en el cuello y cabeza, lo que sugiere un objetivo terapéutico.

El análisis de los cuerpos Paracas han permitido observar que no hay enfermedades evidentes que podrían estar afectando al individuo, mucho menos que estén de manera directa relacionadas con los tatuajes. Los diseños de los tatuajes corporales Paracas son visualmente similares a aquellas imágenes que aparecen con frecuencia en la iconografía de cerámica y textiles. Su ubicación en el cuerpo permite su exhibición, por lo que los diseños debieron ser tatuados para transmitir información social en vez de ser usados como terapia médica.

Aunque los tatuajes pueden cambiar de color, contraste o forma, debido a los cambios de elasticidad de la piel (Kaatz et al. 2008), se ha logrado identificar principalmente diseños zoomorfos, geométricos, figuras míticas, símbolos sociales y diseños abstractos. Todos ellos son motivos plasmados en textiles y cerámica Paracas que han sido transferidos hacia el cuerpo, localizándose generalmente sobre áreas visibles (caras, manos, brazos, piernas), aunque hay muy pocos diseños, principalmente líneas, puntos y diseños zoomorfos, que se localizan entre las piernas y entre los dedos de la mano, en áreas que no son fácilmente visibles.

Entre los tatuajes Paracas destacan las figuras míticas, como el ser oculado y la orca asesina, dos diseños considerados sagrados que se presentan con frecuencia en el arte de Paracas Necrópolis, los cuales denotan poder supernatural y también expresan relaciones sociales (Proulx 2006, Paul 1986). El ser oculado, caracterizado por sus ojos redondos y apéndices, aparece en la mano derecha de la momia 12, es un diseño generalizado que aparece de forma repetitiva en diferentes textiles, vasijas y fachadas de templos Paracas (Massey, 1991), aparentemente fue una figura supernatural 
importante con el cual muchas personas establecieron lazos simbólicos (Paul 1986, 1991).

El tatuaje está asociado a dolor e incomodidad física debido a que produce múltiples lesiones físicas de los tejidos cutáneos del cuerpo. Debido a que los tatuajes Paracas son de diseños complejos, numerosos (generalmente de 10 tatuajes a más por zona corporal) y llegan a cubrir entre el $30 \%$ al $50 \%$ de la superficie corporal en la mayoría de los casos, se estima que todo el proceso de tatuado debió tomar meses o años, sometiendo a los individuos a procesos dolorosos por largos periodos hasta lograr la decoración corporal que vemos hoy en los cuerpos momificados.

Es importante considerar la ubicación del tatuaje, pues la intensidad del dolor será mayor en algunas áreas del cuerpo, especialmente en aquellas que tienen poco tejido graso en comparación con otras partes del cuerpo, debido a que los terminales nerviosos están más cerca de la superficie de la piel (Widgerow \& Kalaria, 2012; Widgerow \& California, 2013), como el caso de la cabeza, cuello, las palmas de las manos, dedos, muñeca, cara interior del muslo, rodilla, pantorrilla y tobillo, provocando mayor intensidad del dolor al insertar las agujar de tatuar.

El dolor de la modificación corporal, entre las que se incluye el tatuaje, es una de las razones por las que estas prácticas se han considerado importantes en muchas culturas, ya que da una significación particular a todo rito, además que la vivencia del dolor forma individuos fuertes, resistentes, competitivos y valientes (Morris, 1993, Koziel et al. 2010, Zárate 2011). Aunque todo el proceso resultara largo, doloroso y riesgoso para el individuo por la frecuencia de las lesiones sobre la piel, era en cambio socialmente recompensado por la posición social que otorgaban los tatuajes, las cuales a juzgar por los diseños registrados, podrían estar relacionadas con la jerarquía, el poder espiritual o la jefatura política.
Esta investigación ha explorado sólo uno de los diferentes aspectos del tatuaje visto desde la paleopatología. Ante la limitación de las técnicas y al no hallarse lesiones evidentes sobre la piel, se hace hincapié aquí en la exposición del individuo al dolor como práctica cultural aceptada, lo cual al parecer estaría relacionada al estatus social a juzgar por los diseños tatuados en los cuerpos. Futuros estudios deberían considerar análisis histológicos en busca de esclarecer las técnicas de tatuado y posibles complicaciones dermatológicas asociadas a la práctica.

Finalmente, es importante recalcar la presencia mayoritaria de mujeres en el registro, las cuales presentan tatuajes que abarcan extensas superficies corporales, posiblemente como manifestación simbólica de su rango social. Es necesario ampliar la muestra con el estudio de cuerpos momificados Paracas que se encuentran custodiados en diversas colecciones, lo cual permitirán obtener mayores datos sobre la paleopatología asociada al tatuaje y una mejor comprensión de la modificación corporal dentro de la sociedad Paracas.

\section{REFERENCIAS BIBLIOGRÁFICAS}

Allison, M. (1996). Early mummies from Coastal Peru and Chile. En: Spindler, K. Wilfing, H., Rastbichler-Zissernig, E., zur Nedden, D., Nothdurfter, H. (Eds.), Human Mummies. Springer, Vienna, New York.

Allison, M. J., Lindberg, L., Santoro, C., \& Focacci, G. (1981). Tatuajes y pintura corporal de los indígenas precolombinos de Perú y Chile. Chungara, 7, 218-236.

Alvrus, A., Wright, D., \& Merbs, C., (2001). Examination of tattoos on mummified tissue using infra-red reflectography.

Arons, J.A., Wainwright, D.J. \& Jordon, R.E.(1992) The surgical applications and implications of cultured human epidermis: A comprehensive review. Surgery 111: 4-11. 
Armelagos, G.J. (1969). Disease in ancient Nubia. Science 163, 255-259.

Assis, S., Keenleyside, A., \& Santos A.L., (2013). Beyond the visible world: the role of microscopy in the study of past human conditions. Microscopy and Microanalysis. Vol 19. Suplemento S4. Pp: 41-42.

Aufderheide, A. \& Rodríguez-Martin, C. (1998). The Cambridge Encyclopedia of Human Paleopathology. Cambridge: Cambridge University Press.

Brandsma, J.W., Yoder, L., Macdonald, M. (2005). Leprosy acquired by inoculation from a knee injury. Leprosy Review 2005; 76: 175-179.

Bryson, D., Wright, J. \& Barker, K. (2013). The identification of tattoo designs under coverup tattoos using digital infrared photography. Journal of Visual Communication in Medicine, 36 (3/4): 104-110.

Buikstra, J.E., \& Ubelaker, D.H. (1994). Standards for Data Collection from Human Skeletal Remains. Research Series, 44. Arkansas Archaeological Survey, Fayetteville. Chi-Yuang, Y., Ching-Hua, L., \& Yi-Hsueh, Y. (2010). Human body surface area database and estimation formula. Burns, 36: 616-629.

Clarkson, H \& Birch, W. (2013). Tattoos and Human Identification: Investigation into the Use of X-Ray and Infrared Radiation in the Visualization of Tattoos. Journal of Forensic Science, 58: 1264-1272.

Cockburn, A., Cockburn, E., \& Reyman, T. (1998). Mummies, Disease and Ancient Cultures. Cambridge: Cambridge University Press. 402 páginas.

Crecelius, C. (2013). Soft Tissue Trauma. Journal of the Oral and Maxillofacial Surgery Clinics, 21: 1: 49-60.

Dembo,A. \& Imbelloni, J.(1938). Deformaciones intencionales del cuerpo humano de carácter étnico. Humanior Biblioteca del Americanista Moderno, Edicion José Anesi, Buenos Aires. 348 páginas.

Dorfer, L., Moser, M. Spindler, K., Bahr, F, Egarter-Vigl, E., \& Dohr, G. (1998). 5200-yearold acupuncture in central Europe?. Science 282, 242-243.
Dorfer, L., Moser, M. Bahr, F, Spindler, K., Egarter-Vigl, E., Guillen, S., \& Dohr, G., Kenner, T., (1999). A medical report from the stone age?. Lancet 354: 1023-1025.

Drage, L., Ecker, P., Orenstein, R., Phullips,

K \& Edson, R. (2009). An outbreak of Mycobacterium chelonae infections in tattoos. Journal of the American Academy of Dermatology, 62 (3): 501-506.

Drewal, H. J., \& Drewal, M. T. (1983). Gẹlẹdẹ: Art and female power among the Yoruba (Vol. 565). Indiana University Press.

Field, H. (1958). Body-marking inSouthwestern Asia. Cambridge, Peabody Museum of Archaeology and Ethnology, Harvard University, vol. XLV, 1.

Faris, J.C. (1972). Nuba personal art, Londres:

Duckworth

Fattahi, T. (2011). Reoperative Soft Tissue

Trauma, Journal of the Oral and Maxillofacial Surgery Clinics, 23: 63-71.

Fornaciari, G., Castagna, M., Viacava, P., Tognetti, A., Bevilacqua, G., \& Segura, E.L. (1992). Chagas'disease in a Peruvian Inca Mummy. The Lancet, 339: 128-129.

Frame, M. (1991). Structure, Image, and Abstraction: Paracas Necrópolis Headbands as System Templates. En: A. Paul (ed.). Paracas Art \& Anchitecture. Object \& context in South Coastal Peru, 110-171.

Franco, R. (2008). La Señora de Cao. En (K. Makowski, Ed.). Señores de los Reinos de la Luna, 280-287. Banco de Crédito del Perú, Lima.

Ghorpade, A. (2009). Ornamental tattoos and skin lesions. International journal of dermatology, 48(1), 11-13.

Gerszten, E., \& Allison, M., (1991). Human soft tissue tumors in paleopathology. En: D. J. Ortner y A. C. Aufderheide (Eds). Human paleopathology, Current syntheses and Future options (257-260). Washington. Smithsonian Institution Press.

Guerrero-Sala, L., (2002). Florilegio de paleopatología vascular: paleoangiología. Angiologia, 54 (6): 492-499. 
Handy, W. C. (1922). Tattooing in the Marquesas. Bulletin of the Bernice P. Bishop Museum, krauss reprint, 1971.

Hogsberg, T., Hutton Carlsen, K \& Serup, J. (2012). High prevalence of minor symptoms in tattoos among a young population tattooed with carbon black and organic pigments. Journal of the European Academy of Dermatology and Venereology, 27 (7): 846-852.

Hunt, D. \& Hopper, L. (1996). Non-invasive investigations of human mummified remains by radiographic techniques. En: K. Sindler, H. Wilfing, E. Rastbichler-Zissernig, D. zur Nedden y H. Nothdurfter, (Eds.). The Man in the Ice, Volume 3 (pp 15-31). Wien \& New York: Springer-Verlag.

Juhas, E., English III, J. (2013). TattooAssociated Complications. Journal of North American Society for Pediatric and Adolescent Gynecology, 26 (2): 125-129

Kaatz, M., Elsner, P. \& Bauer, A. (2008): Body-modifying concepts and dermatologic problems: tattooing and piercing. Clinics in Dermatology, 26: 35-44.

Kaufmann, F. (1999). El Arte textil de Paracas.

En J. A. de Lavalle \& R. Lavalle, (Eds.). Tejidos Milenarios Del Perú; 143-234. Integra. Lima.

Kapel, H., Kromann, N., Mikkelson, F, \& Rosenly, E (1991). Tattooing. En J.P. H. Hansen et al (Eds). The Greenlans Mummies (pp. 102115). London: British Museum Press.

Kazandjieva, J. \& Tsankov, N. (2007). Clinics in Dermatology, 25: 375-382

Koziel, S., Kretschmer, W. \& Pawlowski, B. (2010). Tattoo and piercing as signals of biological quality. Evolution and Human Behavior, 31 (3); 187-192.

Lehner, K., Santarelli, F., Vasold, R., Maisch, T, Konig, B., Landthaler, M\& Baümler, W. (2011). Black tattoo inks in skin - A hazardous chemical cocktail?. Photodiagnosis and Photodynamic Therapy, 8 (2): 201.

Liebl, H., \& Kloth, L. (2012). Skin cell proliferation stimulated by Microneedles. Journal of the American College of Clinical Wound Specialist, (4) 1: 2-6.
Lombardi,G.(1994).DeteccióndeMycobacterium tuberculosis en una momia de la cultura Nazca con mal de Pott. Universidad Peruana Cayetano Heredia, Lima.

Longo, C., Scope, A., Lallas, A., Zalaudek, I, Moscarella, E, Gardini, S., Argenzianos, G., \& Pellacani, G. (2013). Blue lesions. Dermatologic Clinics, 31 (4): 637-647.

Maita, P. K. \& Minaya, E. E. (2013). El uso de reflectografía infrarroja en el registro de tatuajes en momias Paracas-Necrópolis. Arqueología y Sociedad, 26: 117-130. Lima.

Massey, S. (1991). Social and Political Leadership in the Lower Ica Valley. En: A. Paul (Ed.). Paracas Art \& Architecture. Object \& context in South Coastal Peru, 315-348.

Morris, D. (1993). La cultura del dolor. Editorial Andres Bello. Santiago de Chile.

Moser, M., Dorfer, L., Bahr, F, Egarter-Vigl, E., Dohr, G., Kenner, T., (1999). Are Ötzi's tattoos acupuncture? - skin markings on the Tyrolean iceman may have been treatment for his ills. Discovering Archaeol 1: 16-17.

Nishioka, S de A., Gyorkos, T.W. (2001). Tattoos as risk factors for transfusion-transmitted diseases. International Journal of Infectious Diseases, 5: 27-34

Ortner, D., (2011). Human skeletal paleopathology. International Journal o Paleopathology 1: 4-11

Pabst, M. A., Letofsky-Papst, I., Bock, E., Moser, M., Dorfer, L., Egarter-Vigl, E., \& F. Hofer. (2009). The tattoo of the Tyrolean Iceman: a light microscopical, ultrastructural and element analytical study. Journal of Archaeological Science 36: 2335-2341

Pabst, M. A., Letofsky-Papst, I., Moser, M., Spindler, K., Bock, E., Wilhelm, P., Dorfer, L., Geigl, J., Auer, M., Speicher, F \& \& F. Hofer. (2010).Different staining substances were used in decorative and therapeutic tattoos in a 1000-year-old Peruvian mummy. Journal of Archaeological Science 37: 3256-3262.

Paul, A. (1986). Continuity in Paracas Textile Iconography and Its Implications for the meaning of Linear Style Images. En: The Junius Bird Conference on Anden Textiles, April $7^{\text {th }}$ and $8^{\text {th }}$, 1984, ed. Ann Pollard Rowe, pp. 81-99. Washington, D. C: Textile Museum. 
Paul, A. (1991) Paracas Necropolis Bundle 89: A description and discussion of its contents. En: A. Paul (ed.). Paracas Art \& Architecture. Object \& context in South Coastal Peru, 172-221.

Prolux, D. (2006). A sourcebook of Nasca ceramic iconography. University of Iowa Press.

Ruiz, A. (1995). Sobre el hallazgo de momias tatuadas en Huacho. Boletín del Museo de Arqueología y Antropología de la Universidad Nacional Mayor de San Marcos, 6-7.

Ruiz, A. (1990). El hombre tatuado de Huacho. Los especiales de Huacho. Año 1. Nro. 3. Huacho.

Sawyer, A.R. (1960). Paracas Necropolis Headdress and face ornaments. The textile museum, 1-4.

Searight, S. (1984). The use and function of tattooing on Moroccan Women. New Haven, CT: HRAF, Inc.

Smith, G. S. \& Zimmerman, M. R. (1975). Tattooing found on a 1600 year old frozen mummified body from St. Lawrence Island, Alaska. American Antiquity 40, 433-437.

Smith, M. O. (2013). Paleopathology. En E. A. Digiangi y M.K. Moore (Eds.). Research methods in Human Skeletal Biology, (pp. 181-217).

Spindler, K. (1994). The Man in the Ice. New York; Harmony Books.

Stewart, T.D. (1943). Skeletal remains from Paracas, Perú. American Journal of Physical Anthropology 1: 47-63

Stocum, D. (2012). Repair of skin by fibrosis. Regenerative Biology and Medicine, Second Edition: 21-42.

Swami, V., \& Harris, A. S. (2012). Body Art: Tattooing and Piercing. En: Encyclopedia of Body Image and Human Appearance: 58-65.

Tello, J. (1929). Antiguo Perú: primera Epoca. Lima. Comisión Organizadora del Segundo Congreso Sudamericano de Turismo.

Tello, J. (1956). Paracas. Primera parte. Gráfica Scheuch, Lima.

Tello, J. \& Mejía, T. (1979). Paracas. Segunda Parte. Cavernas Necrópolis. Universidad Nacional Mayor de San Marcos. Dirección universitaria de Biblioteca y Publicaciones. Lima.
Ubelaker, D.H. (1999). Human Skeletal Remains. $3^{\text {rd }}$. Edition. Washington, D.C.: Taraxacum.

Vásquez, V., Franco, R., Rosales, T., Rey., I., Tormo, L., \& Álvarez, B. (2013). Estudio microquímico mediante MED-EDS (análisis de energía dispersiva por rayos $\mathrm{X}$ ) del pigmento utilizado en el tatuaje de la Señora de Cao. Revista ARCHAEOBIOS Nro. 7. Vol. 1.

Vivar, J. (2008). Restos humanos tatuados procedentes de Huaura. Boletín de Lima. Vol. XXX, 152: 5-8.

Vreeland, J. (1998). Mummies of Perú. En: A. Cockburn, E. Cockburn \& T. Reyman (eds.). Mummies, Disease \& Ancients Cultures, 154-189.

White, T.D., Black, M.T., Folkens, PA., (2012). Human Osteology. Third Edition. San Diego: Academic Press.

Widgerow, A.D., \& Kalaria, S., (2012). Pain mediators and wound healing. Burns, 38 (7): 951-959.

Widgerow, A.D., \& California, I., (2013). Pain and the healing wound. Wound Healing Southern Africa, 6 (1): 8-11.

Wittmers, L., Aufderheide, A.C., \& Buikstra, J. (2011). Soft tissue preservation system: Applications. International Journal of Paleopathology 1: 150-154.

Wolff, I., Klaus, I.L., \& Klajn. D. S. (2009). Dermatología en Medicina General. $7 \mathrm{ma}$. Edición, Buenos Aires: Médica Panamericana.

Yacovleff, E \& J.C. Muelle. 1934. Un fardo funerario de Paracas. Revista del Museo Nacional. Vol. III: 63-153. Lima.

Zárate, Mirna. (2011). Usos del cuerpo y del dolor en prácticas extremas. Recuperado de: http://incorporare.wordpress.com/2011/08/03/ usos-del-cuerpo-y-del-dolor-en-practicas-extremas/

Zimmerman, M. R. (1980). Aleutian and Alaskan mummies. En A. Cockburn y E. Cockburn (Eds.). Mummies, Disease and Ancient Cultures, (pp. 118-134). Cambridge: Cambridge University Press. 